\title{
KEBERADAAN AJARAN BATHARA KATONG DI KALIWUNGU KENDAL
}

\author{
Fella Sufa Nimasnuning Nur Uyun
}

Jurusan Bahasa dan Sastra Jawa, Fakultas Bahasa dan Seni, Universitas Negeri Semarang, Indonesia

\section{Info Artikel}

Sejarah Artikel:

Keywords:

Ajaran, Tradisi, Budaya

\begin{abstract}
Abstrak
Bathara Katong merupakan salah satu leluhur yang menyiarkan agama Islam di Kaliwungu. Penghargaan Kaliwungu sebagai kota santri tidak terlepas dari peran penting Bathara Katong, warna masyarakat Kaliwungu yang religius hingga saat ini merupakan salah satu pengaruh ajaran Bathara Katong.
\end{abstract}

Data penelitian ini berupa ajaran Bathara Katong yaitu tradisi lisan dan tradisi bukan lisan. Sumber data penelitian ini adalah data dari informan yaitu juru kunci makam Sunan Katong di Kaliwungu, juru kunci tempat sembahyang Sunan Ampel (nama lain Sunan Katong) di Kendal kota, tokoh masyarakat Kaliwungu, tokoh masyarakat Kendal, dan masyarakat umum Kaliwungu. Pengumpulan data penelitian ini menggunakan teknik observasi, wawancara, dan dokumentasi. Kemudian data yang diperoleh dianalisis menggunakan metode analisis deskriptif kualitatif.

Hasil penelitian ini yaitu ajaran Bathara Katong di Kaliwungu ada yang masih rutin dijalankan, dan ada yang sudah jarang dilaksanakan, namun sebagian besar masyarakat Kaliwungu tidak mengetahui bahwa ajaran tersebut merupakan ajaran Bathara Katong.

Ajaran Bathara Katong di Kaliwungu penting untuk dilestarikan tidak hanya oleh masyarakat Kaliwungu namun juga oleh tokoh masyarakat, masyarakat Kaliwungu harus berani mengakui bahwa warna masyarakat Kaliwungu hingga saat ini merupakan hasil perjuangan leluhur seperti Bathara Katong.

\section{Abstraks}

Bathara Katong is one of the ancestors who broadcast Islam in Kaliwungu. The Kaliwungu award as a city of santri is inseparable from the important role of Bathara Katong, the color of the religious Kaliwungu community to date is one of the influences of the teachings of Bathara Katong. This research data is in the form of Bathara Katong teachings namely oral traditions and traditions rather than oral. The data sources of this research are data from informants namely the caretaker of the tomb of Sunan Katong in Kaliwungu, the caretaker of the prayer place of Sunan Ampel (another name is Sunan Katong) in Kendal city, Kaliwungu community leaders, Kendal community leaders, and the Kaliwungu general public. The data collection of this study uses observation, interview, and documentation techniques. Then the data obtained were analyzed using qualitative descriptive analysis method. The results of this study are the teachings of Bathara Katong in Kaliwungu which are still routinely carried out, and some are rarely implemented, but most of the Kaliwungu people do not know that the teachings are the teachings of Bathara Katong. The Bathara Katong teaching in Kaliwungu is important to be preserved not only by the 
Kaliwungu community but also by community leaders, the Kaliwungu community must dare to admit that the colors of the Kaliwungu community up to now are the result of ancestral struggles such as Bathara Katong.

(C) 2016 Universitas Negeri Semarang

Alamat korespondensi:

ISSN 2252-6463

Gedung B8 Lantai 1 FBS Unnes

Kampus Sekaran, Gunungpati, Semarang, 50229

E-mail: sutasoma@mail.unnes.ac.id

\section{Pendahuluan}

Kaliwungu merupakan sebuah kota kecil di Kendal yang dikenal dengan sebutan kota santri. Penghargaan Kaliwungu sebagai kota santri tidak lepas dari peran penting leluhur Kaliwungu seperti Bathara Katong/Sunan Katong/Sunan Ampel (Sunan Ampel merupakan sebutan Bathara Katong/Sunan Katong di daerah Kendal tepatnya di Ampel dan memiliki padepokan di daerah Ampel Kulon bernama padepokan Ampelgading). Bathara Katong adalah leluhur Kaliwungu asal Ponorogo, dalam buku yang berjudul Wali-Wali Mataram Kendal Sunan Katong dan Pakuwaja yang ditulis oleh Rochani disebutkan bahwa banyak catatan yang menerangkan Bathara Katong adalah putra Prabu Brawijaya, namun Brawijaya siapa yang dimaksud ternyata ada tiga catatan. 
Catatan pertama bahwa Bathara Katong adalah putra Brawijaya I, yaitu Prabu Kertawijaya dari istri asal Champa. Catatan kedua Bathara Katong putra Prabu Brawijaya dari istri asal Bagelen. Adapun catatan ketiga Bathara Katong putra Brawijaya V, Prabu Kertabhumi, sedangkan dalam catatan di makam Sunan Katong, Sunan Katong merupakan cucu dari Bathara Katong.

\section{Bathara Katong/Sunan Katong/}

Sunan Ampel bersama pasukannya mendarat di Kaliwungu dan memilih tempat di pegunungan Penjor atau Pegunungan Telapak Kuntul Nglayang. Beberapa tokoh dalam rombongannya pada cerita tutur disebutkan ada Ten Koe Pen Jian Lien (Tekuk Penjalin/Syeh Abdurrahman), Han Bi Yan (Gembyang/Syeh Abdullah), dan Raden Panggung atau Raden Arya Witiswara (Wali Joko). Tekuk Penjalin dan Gembyang merupakan putra dari Syeh Wali Lanang. Tekuk Penjalin adalah seorang guru mengaji dan imam di Kaliwungu sedangkan Gembyang seorang guru mengaji dan imam di Kendal, Wali Joko sendiri merupakan keturunan dari Prabu Brawijaya, Raja Majapahit.

Sebelum Bathara Katong diyakini datang ke Kaliwungu untuk menyebarkan agama Islam, leluhur Kaliwungu seperti Eyang Nitinegara dan lainnya telah lebih dulu datang ke Kaliwungu untuk menyebarkan agama Islam, sehingga sebelum Bathara Katong menyebarkan agama Islam di Kaliwungu, leluhur Kaliwungu sebelum Bathara Katong telah lebih dulu menyebarkan agama Islam lewat beberapa ajarannya. Dengan begitu, ada dugaan bahwa ajaran Bathara Katong merupakan ajaran leluhur
Kaliwungu yang dipersonifikasikan dengan nama Bathara Katong, sehingga ada kemungkinan bahwa Bathara Katong hanyalah sosok simbolis ajaran leluhur Kaliwungu, dengan ajaran-ajaran tersebut Kaliwungu pada akhirnya mendapat penghargaan sebagai kota santri, oleh sebab itu peneliti memilih ajaran Bathara Katong sebagai fokus penelitian agar mengetahui bagaimanakah keberadaan ajaran Bathara Katong di Kaliwungu, apakah masyarakat Kaliwungu mengetahui ajaran Bathara Katong yang berupa lisan (shalawat macan putih dan wejangan) dan bukan lisan (khaul dan blantenan), atau masyarakat Kaliwungu menjalankan ajaran tersebut namun tidak mengetahui bahwa ajaran tersebut merupakan warisan dari leluhur Kaliwungu yang dipersonifikasikan dengan nama Bathara Katong.

\section{Metode Penelitian}

Penelitian ini menggunakan pendekatan penelitian deskriptif kualitatif sebab penelitian ini dimaksudkan untuk memahami fenomena tentang apa yang dialami oleh subjek penelitian yaitu perilaku, persepsi, motivasi, dan tindakan dengan cara deskripsi dalam bentuk kata-kata dan bahasa pada suatu konteks khusus yang alamiah dan dengan memanfaatkan berbagai metode alamiah. Penelitian ini bertujuan untuk memahami fenomena masyarakat Kaliwungu tentang bagaimana keberadaan ajaran Bathara Katong di Kaliwungu, apakah masih ada dan dijalankan ataukah sudah tidak dijalankan.

Data penelitian ini adalah ajaran 
Bathara Katong di Kaliwungu Kendal yang berupa tradisi lisan (shalawat macan putih dan wejangan) dan tradisi bukan lisan (blantenan dan khaul). Sumber data penelitian ini adalah data dari informan yaitu Bapak Sunoto juru kunci makam Sunan Katong di Kaliwungu, Bapak Erpai juru kunci tempat sembahyang Sunan Ampel (nama lain Sunan Katong) di Kendal, tokoh masyarakat Kaliwungu Bapak Zaenuri, tokoh masyarakat Kendal Eyang Abiyasa, budayawan Kendal Bapak Sonny Wisnu Murti, dan masyarakat umum Kaliwungu.

Teknik pengumpulan data yang digunakan dalam penelitian ini adalah observasi, wawancara, dokumentasi. Analisis data pada penelitian ini menggunakan analisis terkait dengan teori folklor. Prosedur analisis yang dilakukan yaitu: a) verifikasi data; b) mengaitkan hasil wawancara dengan teori; c) menemukan bentuk ajaran; d) mencari nilainilai pada hasil wawancara; mendeskripsikan keberadaan ajaran.

\section{Hasil Penelitian}

Bathara Katong adalah salah satu leluhur Kaliwungu asal Ponorogo yang menyebarkan agama Islam di Kaliwungu. Di Kaliwungu, Bathara Katong lebih dikenal dengan nama Sunan Katong, sedangkan di daerah Kendal kota Bathara Katong lebih dikenal dengan nama Sunan Ampel. Sebelum beliau datang ke Kaliwungu, beliau datang ke daerah Kendal kota tepatnya di Ampel Kulon dan memiliki padepokan Ampelgading. Setelah menyebarkan agama Islam di Kendal, kemudian beliau datang ke Kaliwungu (pada saat itu belum dinamakan Kaliwungu) dan memilih pegunungan Penjor.

Menurut cerita tutur masyarakat Kaliwungu yang telah dibukukan berjudul Wali-Wali Mataram Kendal Sunan Katong dan Pakuwaja ditulis oleh Rochani bahwa perkelahian antara Sunan Katong dan Pakuwaja menjadi penyebab lahirnya nama Kaliwungu, sehingga dalam hal ini masyarakat Kaliwungu meyakini bahwa Bathara Katong merupakan sosok historis yang pernah hidup di dunia ini, namun jika dipahami lebih dalam tentang cerita Bathara Katong di Kaliwungu yang banyak mengandung simbol atau pralambang, tidak berlebihan jika Bathara Katong hanyalah sosok simbolis. Ada kemungkinan bahwa maksud dari ajaran Bathara Katong merupakan ajaran leluhur Kaliwungu yang dipersonifikasikan dengan nama Bathara Katong.

Ajaran Bathara Katong/Sunan Katong/Sunan Ampel memiliki dua bentuk ajaran yaitu: a) tradisi lisan yang berupa shalawat macan putih dan wejangan Bathara Katong; dan b) tradisi bukan lisan yang berupa blantenan dan khaul. Dahulu masyarakat Kaliwungu menjalankan ajaran Bathara Katong tersebut secara rutin sehingga pada akhirnya Kaliwungu mendapat penghargaan sebagai kota santri.

\section{Keberadaan Ajaran}

Ajaran Bathara Katong di Kaliwungu yaitu tradisi lisan yang berupa shalawat macan putih dan wejangan, dan tradisi bukan lisan seperti kesenian blantenan dan khaul, keberadaan ajaran Bathara Katong di 
Kaliwungu masih ada yang tetap dilestarikan, ada juga yang sudah jarang, namun ada juga yang masih ada namun pelaksanaannya telah mengalami perubahan. Sebagian besar masyarakat Kaliwungu tidak mengetahui ajaran Bathara Katong di Kaliwungu, namun mereka melaksanakan ajaran tersebut dengan kata lain masyarakat Kaliwungu hanya mau menikmati ajaran Bathara Katong namun tidak mengetahui siapa yang mewariskan, akibatnya masyarakat Kaliwungu kurang menghargai jerih payah leluhurnya sendiri, bahkan ada yang tidak mengenal Bathara Katong, seperti yang dituturkan Bapak Erpai, juru kunci tempat sembahyang Sunan Ampel di Kendal.

Berdasarkan hasil penelitian ini mengenai keberadaan ajaran Bathara Katong di Kaliwungu Kendal, maka dapat disimpulkan bahwa ajaran Bathara Katong berupa tradisi lisan yaitu shalawat macan putih, wejangan dan tradisi bukan lisan yaitu kesenian blantenan dan khaul yang diajarkan Bathara Katong. Secara umum ajaran Bathara Katong bertujuan untuk menyiarkan agama Islam, mengajarkan tentang bagaimana hidup selaras vertikal horizontal. Keberadaan ajaran Bathara Katong di Kaliwungu Kendal ada yang masih tetap dilestarikan misalnya shalawat macan putih dan khaul, namun ada juga yang sudah jarang dilakukan seperti blantenan. Sebagian besar masyarakat Kaliwungu tidak mengetahui bahwa shalawat macan putih, blantenan, dan khaul merupakan ajaran Bathara Katong, sehingga terkesan masyarakat hanya mau menikmati akan tetapi kurang mau dan berani mengakui bahwa warna masyarakat Kaliwungu yang ada sampai saat ini adalah bagian besar warisan adi luhung hasil perjuangan gigihnya leluhur Kaliwungu.

\section{Simpulan}

Berdasarkan hasil penelitian ini mengenai keberadaan ajaran Bathara Katong di Kaliwungu Kendal, maka dapat disimpulkan bahwa ajaran Bathara Katong berupa tradisi lisan yaitu shalawat macan putih, wejangan dan tradisi bukan lisan yaitu kesenian blantenan dan khaul yang diajarkan Bathara Katong. Secara umum ajaran Bathara Katong bertujuan untuk menyiarkan agama Islam, mengajarkan tentang bagaimana hidup selaras vertikal horizontal. Keberadaan ajaran Bathara Katong di Kaliwungu Kendal ada yang masih tetap dilestarikan misalnya shalawat macan putih dan khaul, namun ada juga yang sudah jarang dilakukan seperti blantenan. Sebagian besar masyarakat Kaliwungu tidak mengetahui bahwa shalawat macan putih, blantenan, dan khaul merupakan ajaran Bathara Katong, sehingga terkesan masyarakat hanya mau menikmati akan tetapi kurang mau dan berani mengakui bahwa warna masyarakat Kaliwungu yang ada sampai saat ini adalah bagian besar warisan adi luhung hasil perjuangan gigihnya leluhur Kaliwungu.

\section{Daftar Pustaka}

Alatas, Ismail Fajrie. 2014. Pilgrimage and Network Formation in Two Contemporary BA Alawi Awl in Central Java, dalam Journal of Islamic Studies 25, 3, September, 298-324.

Crumrine, N. Ross. 2009. Ritual Drama and Culture Change, dalam Rural History 12, 4, 
Juni, 361-372.

Danandjaja, James. 2002. Folklor Indonesia: Ilmu Gosip, Dongeng, dan Lain- lain. Jakarta: Pustaka Utama Grafiti.

Endraswara, Suwardi. 2012. Aspek Budi Luhur dan Memayu Hayuning Bawana dalam Sastra Mistik Penghayat Kepercayaan Kaitannya dengan Pendidikan Karakter, dalam Jurnal Pendidikan Karakter, edisi Juni, TH. II, no. 2.

Hamilton, C. A. 2014. Ideology and Oral Traditions, Listening to The Voices 'From Below', dalam Rural History 14, Mei, 67-86.

Kartikasari. 2006. Konflik Sosial dalam Cerita Rakyat Asal Usul Kaliwungu. Skripsi. Universitas Negeri Semarang.

Magnis-Suseno, Franz. 2003. Etika Jawa. Jakarta: Gramedia Pustaka Utama.

Moleong, Lexy. 2007. Metode Penelitian Kualitatif. Bandung: Remaja Rosdakarya. 2009. Metodologi Penelitian Kualitatif. Bandung: Remaja Rosdakarya.

Munib, Achmad, dkk. 2010. Pengantar Ilmu Pendidikan. Semarang: Universitas Negeri Semarang Press.

Rochani, Ahmad Hamam. 2013. Wali-wali Mataram Kendal: Sunan Katong dan Pakuwaja. Semarang: Grafika Citra Mahkota.

Sanjaya, Wina. 2011. Strategi Pembelajaran Berorientasi Standar Proses Pendidikan. Jakarta: Kencana.
Shabariyah, Nunung. 2009. Tradisi Khaul Syeakh Maulana Magribi di Desa Wonobodro Kecamatan Blado Kabupaten Batang. Skripsi. Universitas Negeri Semarang.

Simpson, Jacqueline. 2009. The Local Legend: A Product of Popular Culture, dalam Rural History 2, Januari, 25-35.

Sudjiman, Panuti. 1984. Kamus Istilah Sastra. Jakarta: Gramedia.

Sugiyono. 2010. Metode Penelitian Pendidikan: Pendekatan Kuantitatif, Kualitatif, dan $R \& D$. Bandung: Alfabeta.

Sukirno. 2013. Pengkajian dan Pembelajaran Pitutur Luhur sebagai Pembentuk Karakter Peserta Didik, dalam Jurnal Pendidikan Karakter, edisi Februari, TH. III, no. 1.

Suprijono, Agus. 2013. Konstruksi Sosial Siswa SMA terhadap Mitos Buyut Cili sebagai Tradisi Lisan Sejarah Blambangan, dalam Paramita, Vol. 23, no. 2.

Tamney, Joseph B. 1980. Functional Religiosity and Modernization in Indonesia, dalam Sociology of Religion, 41, 5565.

Wagiran, 2012. Pengembangan Karakter Berbasis Karifan Lokal Hamemayu Hayuning Bawana (Identifikasi Nilai-nilai Karakter Berbasis Budaya), dalam Jurnal Pendidikan Karakter, edisi Oktober, TH. II, no. 2. 